\title{
Application of nanofluids for treating fines migration during hydraulic fracturing: Experimental study and mechanistic understanding
}

\author{
Ramin Moghadasi ${ }^{1}$, Alireza Rostami ${ }^{1}$, Abdolhossein Hemmati-Sarapardeh ${ }^{2 \oplus *}$ \\ ${ }^{1}$ Department of Petroleum Engineering, Petroleum University of Technology, Ahwaz, Iran \\ ${ }^{2}$ Department of Petroleum Engineering, Shahid Bahonar University of Kerman, Kerman, Iran
}

(Received March 2, 2019; revised April 5, 2019; accepted April 8, 2019; available online April 18, 2019)

\section{Citation:}

Moghadasi, R., Rostami, A.,

Hemmati-Sarapardeh, A. Application of nanofluids for treating fines migration during hydraulic fracturing: Experimental study and mechanistic understanding.

Advances in Geo-Energy Research, 2019,

3(2): 198-206, doi:

10.26804/ager.2019.02.09.

Corresponding author:

*E-mail: aut.hemmati@gmail.com

hemmati@uk.ac.ir

Keywords:

Hydraulic fracturing

fines migration

nanosilica

glass beads

core displacement

\begin{abstract}
:
Hydraulic fracturing has emerged as one of the best and most economical methods for enhancing oil recovery from low permeability reservoirs. However, its performance will be negatively affected by fines migration due to the hydraulic fracturing process. In the present study, it has been tried to experimentally investigate the efficiency of synthesized nanosilica particles in reducing fines migration. To this end, two sets of static and dynamic experiments, namely glass bead funnel test and core displacement analysis, were implemented, respectively. In the static test, increasing the soaking time and addition of nanosilica led to the clearer effluent fluid, resulting in fewer concentrations of clay particles in solution. When the mixture of nanosilica and glass beads was available in the solution, a higher differential pressure was obtained during a dynamic condition in comparison to only glass beads, which means the lower permeability of the porous media. Moreover, Derjaguin-Landau-Verwey-Overbeek theory was applied to demonstrate the clay particles absorption on the sand proppants surfaces. Consequently, it was observed that the use of nanosilica particles mixed with sand proppant can effectively reduce fines migration; thereby, it can enhance the hydraulic performance of the fracturing operation.
\end{abstract}

\section{Introduction}

Hydraulic fracturing (HF) is commonly implemented as a production improvement technique in the oil and gas industries (Cipolla, 2009; Haddad and Sepehrnoori, 2015; Li et al., 2015; Sanematsu et al., 2015; Bao et al., 2017; Liu et al., 2018). To date, the application of HF has been well justified. Most importantly, these justifications are associated with the beneficial aspects of HF in resolving jamming effects and assisting production from reservoirs with low permeability. Jamming of the flow occurs due to the circular shape of the well and radial flow behavior near the wellbore. Considering the radial flow pattern, the fluid passes thorough consecutively smaller and smaller areas; consequently, fluid flow will be reduced. A well designed hydraulic fracturing process results in a nearly linear flow behavior around the wellbore region, which causes a reduction in the jamming effects; thereby, higher well productivity is obtained. In addition, HF can create a very permeable conduit in low permeability reservoirs making them economically producible. Theoretically, the performance of a hydraulically fractured reservoir depends on many factors such as fracture fluid characteristics and proppant properties as two important parameters, which should be taken into consideration for a well-designed fracturing job. Fracturing fluid commonly consists of water and some additives like viscosifiers. Proppants are injected inside the hydraulicallyinduced fractures to make them still open after the fracturingfluid leaks off (Wen et al., 2007; Guo et al., 2012; Khanna et al., 2012; Bortolan Neto et al., 2015; Zhang et al., 2015). Therefore, they should have sufficient mechanical properties to resists against the "in-situ" stress which is mainly due to the gravity of the rocks located deep beneath the surface; however, the performance of a fracturing job does not only depend on the proper application and selection of fracturing 
fluid and proppant materials. For instance, the occurrence of fines migration during HF job adversely impacts fracture conductivity which results in reduction of productivity.

Fines are small sized clay particles, which are mostly found in sandstone reservoirs. These tiny particles can move easily with any fluid movement through the reservoir. However, they are displaced much more easily with the wetting phase movement (Yuan and Shapiro, 2011; Zeinijahromi et al., 2012; Civan, 2016). As fines migrate, they get stuck in some other locations, especially at pore throats. As a result, pores will be plugged and productivity will be declined. Fines release is promoted during a fracturing job, which affect fracture conductivity adversely. Therefore, it is of high importance to control fines migration for conducting an efficient fracturing process.

Numerous studies have been performed aiming at controlling fines migration or removing the fines from plugged pores (Assef et al., 2014). Yuan and Wood (2018) addressed fines control and also discussed nanoparticles role in reducing formation damage caused by fines migration. Commonly, acid and non-acid washing are implemented for removing such fines from the near wellbore region. However, these kinds of treatments are only effective temporarily, and pores will be plugged when the treated well is produced for a period of time.

Nanotechnology is a branch of combined science and engineering which has been effectively applied to numerous aspects of engineering. Oil and gas industry has also shown great interests in nano-based materials (Ahmadi and Shadizadeh, 2013; Assef et al., 2014; Franco et al., 2014; Parvazdavani et al., 2014; Shokrlu and Babadagli, 2014; Ezeonyeka et al., 2018; Divandari et al., 2019). Nanoparticles (NPs) have been used in drilling and completion fluids over the last decade. Huang et al. (2010) studied field applications of nano-coated proppants in frac-packing operation to control fines migration. They concluded that nano-coated proppants are efficient in fines control. They postulated that nanoparticles could be effective in fines migration reduction by having high surface forces. Lv et al. $(2015,2019)$ studied the effect of nanoparticle and surfactants for stabilizing the foam as fracturing fluid. They found that $\mathrm{SiO}_{2}$ nanoparticle-surfactant-stabilized foam has a better performance compared to a surfactant-stabilized foam. Also, it leads to lower core permeability damage than a gel-surfactant-stabilized foam. Moreover, NPs have found many applications and have been used as gelation materials, foaming agents, stabilizer of water-in-oil emulsion, filter cake additives, and fluid loss control agents (Binks, 2002; Zakaria et al., 2012; Contreras et al., 2014a, 2014b, 2014c; Borisov et al., 2015; Dai et al., 2015). Furthermore, they have been used as additives for promoting wellbore stability in shales (Gao et al., 2016). Recently, Hoxha et al. (2017) explained the physical mechanism by which shales and nanoparticles interact, and also they described the way that this interaction might actually benefit shale stability.

This research aims to study the application of nanofluids in reducing fines migration after hydraulic fracturing in low permeability reservoirs. To this end, a new type of nanosilica particles is synthesized on the basis of the described syn- thetic route in the work of Choolaei et al. (2012). Then, the synthesized nanoparticles are applied as a new remedy to treat the fines migration phenomenon occurred during the hydraulic fracturing process. Two sets of experiments including glass bead funnel test and core displacement experiment are designed for exploring the impact of nanosilica on fines migration in association with sand proppants. The SEM and Zeta potential tests are used to support the justification of the results. Finally, Derjaguin-Landau-Verwey-Overbeek (DLVO) theory is used to calculate the so-called parameter of disjoining pressure in order to demonstrate the clay particle absorption as the dominant mechanism of fines migration reduction in this study.

\section{Materials and methods}

\subsection{Materials}

In this study, a new type of nanosilica material is synthesized based on the procedure described in the work of Choolaei et al. (2012). We already used this nanoparticle during low salinity water injection to reduce fines migration (Moghadasi et al., 2019a). Lightweight sand proppants with an average mesh size of $50(\sim 300 \mu \mathrm{m})$ and density of $1.6 \mathrm{~g} / \mathrm{cm}^{3}$, and Kaolinite clays with an average size of $3 \mu \mathrm{m}$ were purchased from Nano-Gostar Company, Khuzestan, Iran. Glass beads with an average mesh size of $30(\sim 600 \mu \mathrm{m})$, xanthan gum (XG), double distilled water, and $\mathrm{NaCl}$ slat were supplied by the petroleum research center.

\subsection{Methods}

In this study, two different sets of experiments were conducted to evaluate the effects of nanosilica particles on fines migration during hydraulic fracturing.

\subsubsection{Glass bead packed column}

In the first set, a synthetic core sample was prepared with glass beads packed in a column, which is shown in Fig. 1. To investigate the nanosilica effects, the used glass beads were soaked in solutions of nanosilica with $10 \mathrm{gr}$ sand proppant in $100 \mathrm{cc}$ distilled water for 24 and 72 hours. The solution of nanofluid was prepared with the aid of ultrasonic device supplied by Heilscher-Ultrasonic Technology. In order to maintain a constant temperature condition during the soaking process, the solutions were kept in a beaker inside the oven at a temperature of $25^{\circ} \mathrm{C}$. To determine the nanosilica concentration, the strength of nanosilica and sand proppant mixture against pressure was measured as an indicator. Nanofluids composed of $350 \mathrm{cc}$ water ( $\sim 1 \mathrm{bbl}$ of water), $453.592 \mathrm{gr}$ of $\mathrm{XG}$, and 2, 4 and $8 \mathrm{gr}$ of nanosilica mixed with $10 \mathrm{gr}$ of sand proppant, were prepared. First of all, water and XG were mixed for 20 minutes to make a good viscous medium. Then, the mixture of nanosilica and sand proppant was added to the previously prepared aqueous solution of $\mathrm{XG}$ using a mud balance. Densities of the solutions were roughly measured, which are about $1.089,1.112$ and $1.144 \mathrm{gr} / \mathrm{cc}$, respectively, 

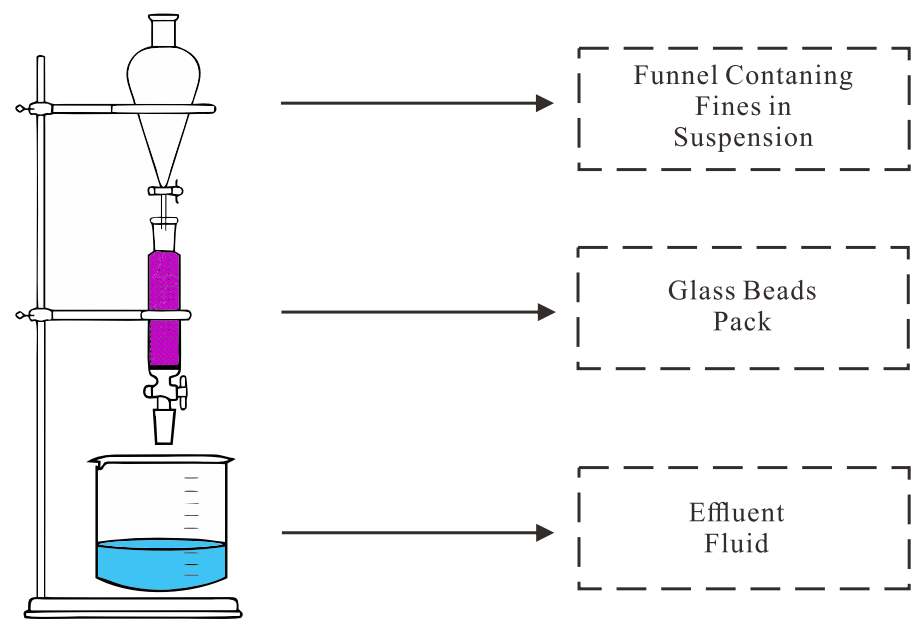

Fig. 1. Glass bead funnel test.

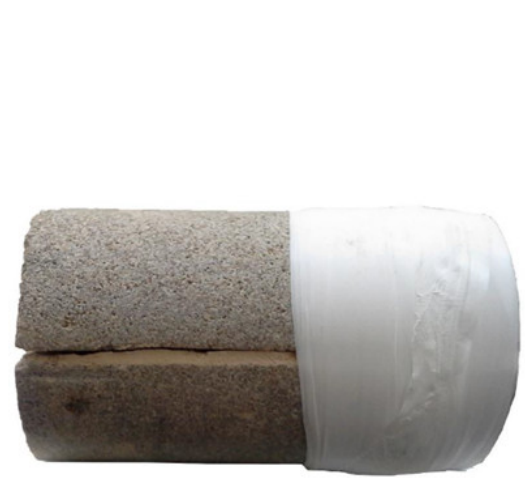

(a)

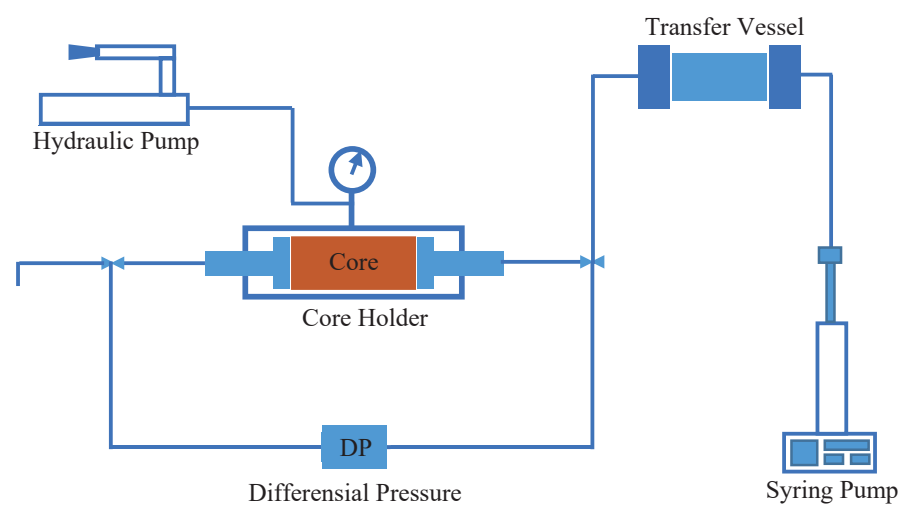

(b)

Fig. 2. (a) Fractured core sample cross view; (b) A schematic representation of core flooding setup (Moghadasi et al., 2019b).

for the abovementioned solutions containing 2,4 and $8 \mathrm{gr}$ nanosilica particles. The prepared solutions were loaded in a high-pressure cell while being subjected to a pressure of 41.369 MPa. Then, the pressure was discharged and the densities were measured, which are about $1.105,1.118$ and $1.185 \mathrm{gr} / \mathrm{cc}$, respectively, for the abovementioned solutions containing 2, 4 and 8 gr nanosilica particles. Consequently, it was observed that the solution containing 4 gr nanosilica particles has higher resistance to pressure as it indicated the least density change. A mixture of suspended fines in a brine solution of $50,000 \mathrm{ppm} \mathrm{NaCl}$ was prepared. This solution was injected from the top of the packed column under the gravity force. The effluent fluid was collected and visually inspected to detect changes in solution clarity, which is a direct indication of outlet clay concentrations.

\subsubsection{Core displacement experiment}

In the second set of our experiments, a six inches' sandstone core plug was used and cut into two samples, then each of them was fractured alongside its longitudinal axis. First, 10 gr of sand proppant was put between two sub plugs, and then it was wrapped with a plastic sleeve as shown in Fig. 2(a).
Next, the synthetic core plug was placed in a core holder, and overburden pressure was set to $27.57 \mathrm{MPa}$ in order to simulate a fractured and porous-like medium. The solution of clay particles in $50,000 \mathrm{ppm} \mathrm{NaCl}$ solution was loaded in a transfer vessel, and core flooding process was started at a rate of $0.5 \mathrm{ml} / \mathrm{min}$ for about 8 minutes. Afterward, the rate was changed to 1.0 and $1.5 \mathrm{cc} / \mathrm{min}$, both of which continued for nearly 8 minutes. Pressure across the core sample was measured using a pressure transducer. The same procedure was repeated for the mixture of $4 \mathrm{gr}$ nanosilica with $10 \mathrm{gr}$ sand proppant. During core flooding experiments, the temperature was set to $25^{\circ} \mathrm{C}$. A schematic of the core flood apparatus is shown in Fig. 2(b).

\section{Results and discussion}

In this study, the effect of nanosilica on fines migration during hydraulic fracturing was investigated through two different sets of experiments. In the first set, a flow test under gravity forces was performed on a packed column of glass beads. Glass beads were initially soaked in the solutions of sand proppant, and a mixture of sand proppant and nanosilica for 24 and 72 hours. The concentration of sand proppant in 100 


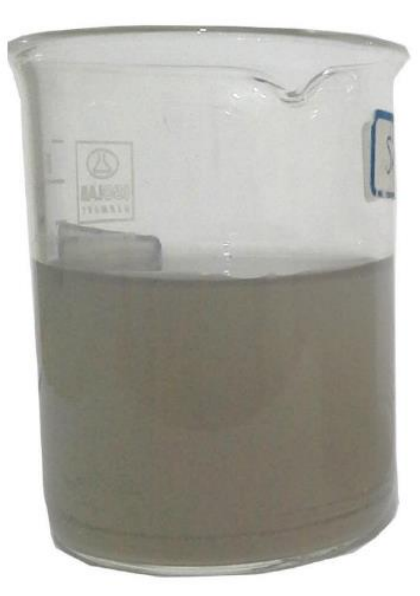

(a)

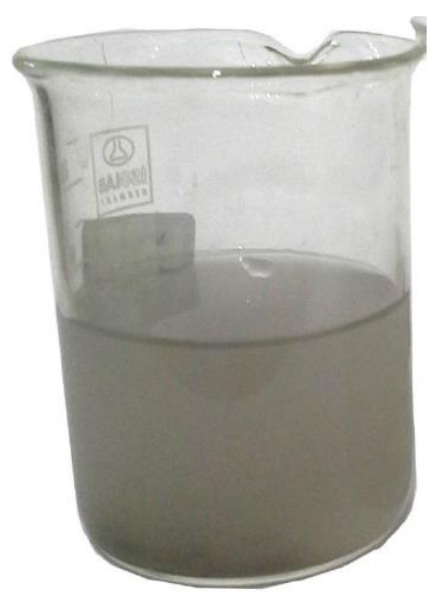

(b)

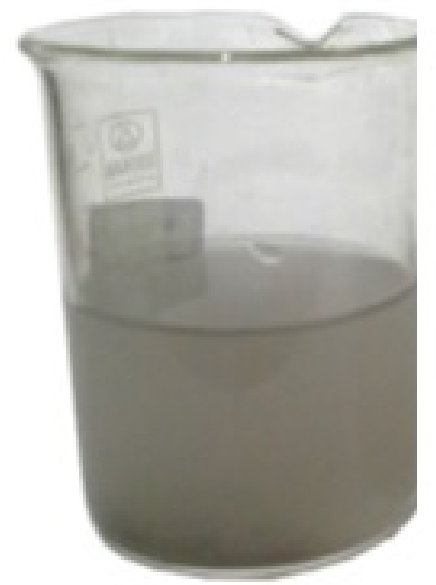

(c)

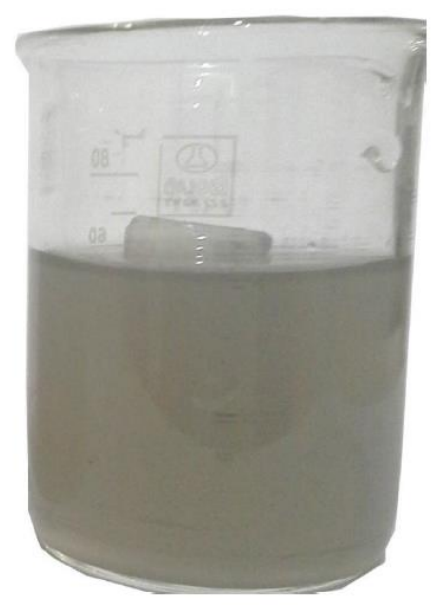

(d)

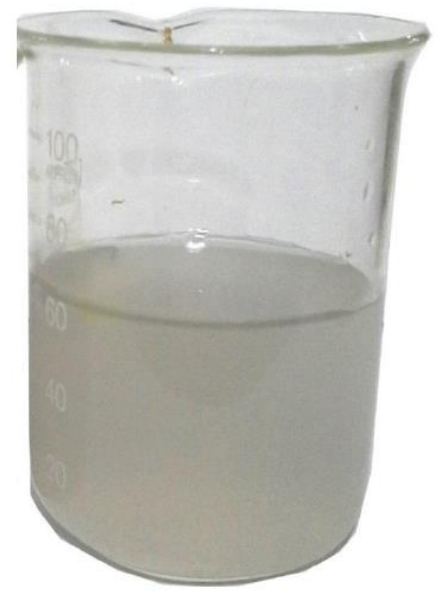

(e)

Fig. 3. Effluent collected fluids during glass beads funnel test: (a) Base fluid containing clay particles in 50000 ppm NaCl solution; (b) Collected effluent solution from glass beads soaked in proppant solution for $24 \mathrm{hrs}$; (c) Collected effluent solution from glass beads soaked in proppant solution for 72 hrs; (d) Collected effluent solution from glass beads soaked in proppant and nanosilica solution for 24 hrs; (e) Collected effluent solution from glass beads soaked in proppant and nanosilica solution for $72 \mathrm{hrs}$.

cc of distilled water was fixed to $10 \mathrm{gr}$, but the concentration of nanosilica was determined based on the highest resistance to the pressure that can be achieved by a mixture of proppant and nanosilica. Effluent fluids were collected and visually inspected for any changes occurred in their clarity compared with the base fluid, which is indicated in Fig. 3. A comparison between Figs. 3(a) and 3(b) shows no significant change in solution clarity for the case that glass beads were soaked in a solution containing only sand proppants. It is also obvious that increasing soaking time from 24 to 72 hours did not cause any change (see Figs. 3(b) and 3(c)). On the other hand, changes in solution clarity were easily detectable when glass beads were soaked with nanofluid (see Figs. 3(a), 3(d) and 3(e)). By comparison between Figs. 3(d) and 3(e), it is found that the effluent fluid gets clearer as the soaking time increases from 24 to 72 hours. The clarity of the solution is directly correlated with the solution's clay content. The higher the clay content, the darker the solution (less clarity) and vice versa. As comparisons showed, the effluent solution was clearer when the glass beads were soaked in nano-based fluid. These qualitative observations suggest that nanosilica could be effective in fines migration control. The underlying mechanism goes back to the process by which nanosilica particles get absorbed on glass beads. Fig. 4(a) shows the SEM image of glass beads with nanosilica particles absorbed on their surfaces. Consequently, clay particles that are negatively charged (Driscoll, 1972), can get filtered as they get absorbed on glass bead surfaces.

Fig. 4(b) presents the Zeta potential (ZP) measurement (using Zeta analyzer apparatus-ELSZ-2000 series supplied by Otsuka Electronics Company) for nanosilica used in this study. As it can be shown, its value is positive and is roughly about 50 $\mathrm{mV}$ on average. A positive Zeta potential value indicates that Nanosilica particles applied in this study, are able to absorb negatively charged clay particles; thereby, preventing them from being passed through the packed column. It should be noted that Zeta potential is a method for the determination of the electrostatic potential at the electrical double layer 


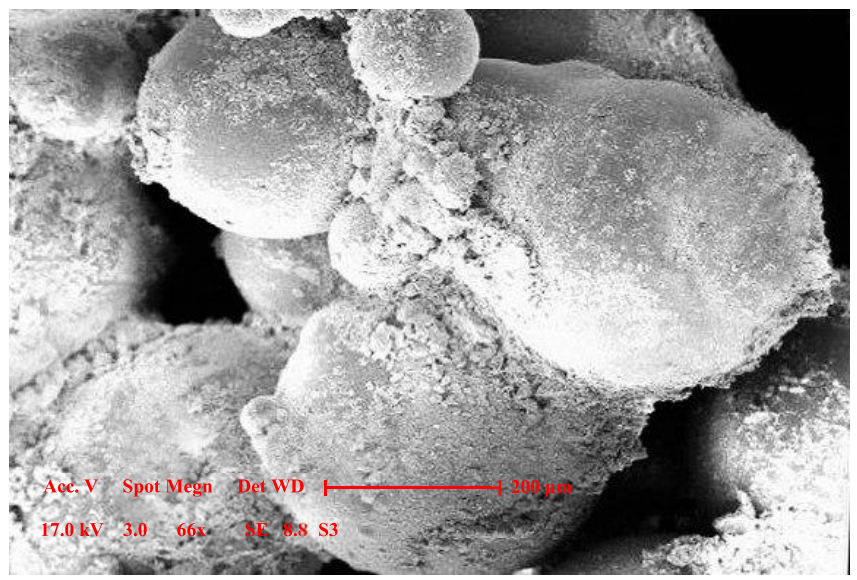

(a)

Zeta Potential Distribution

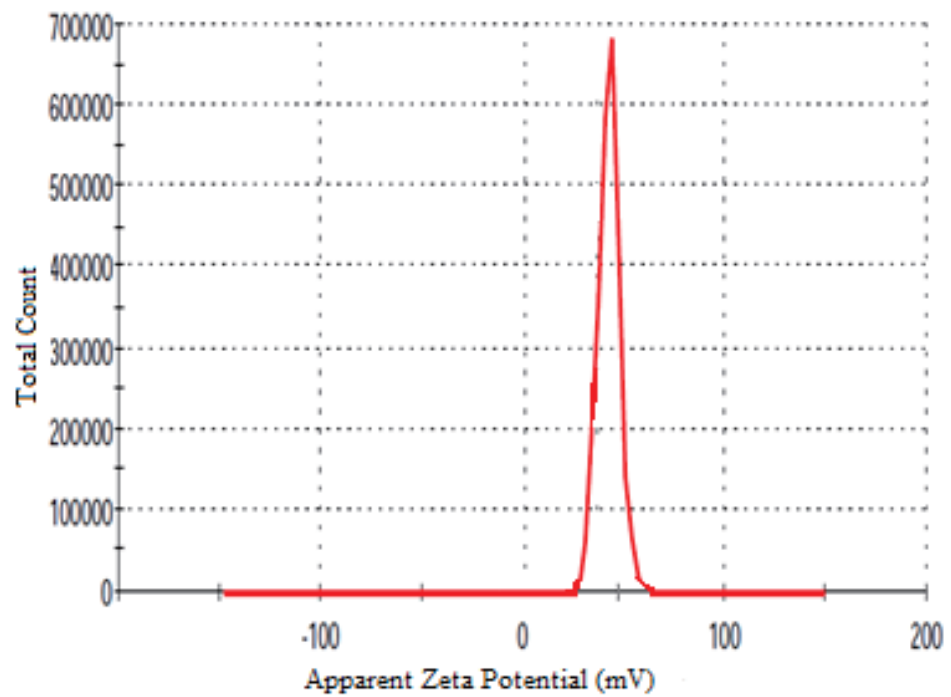

(b)

Fig. 4. (a) SEM image of absorbed nanosilica on glass beads; (b) Zeta potential of nanosilica measured at $25^{\circ} \mathrm{C}$ and $\mathrm{pH}=7$.

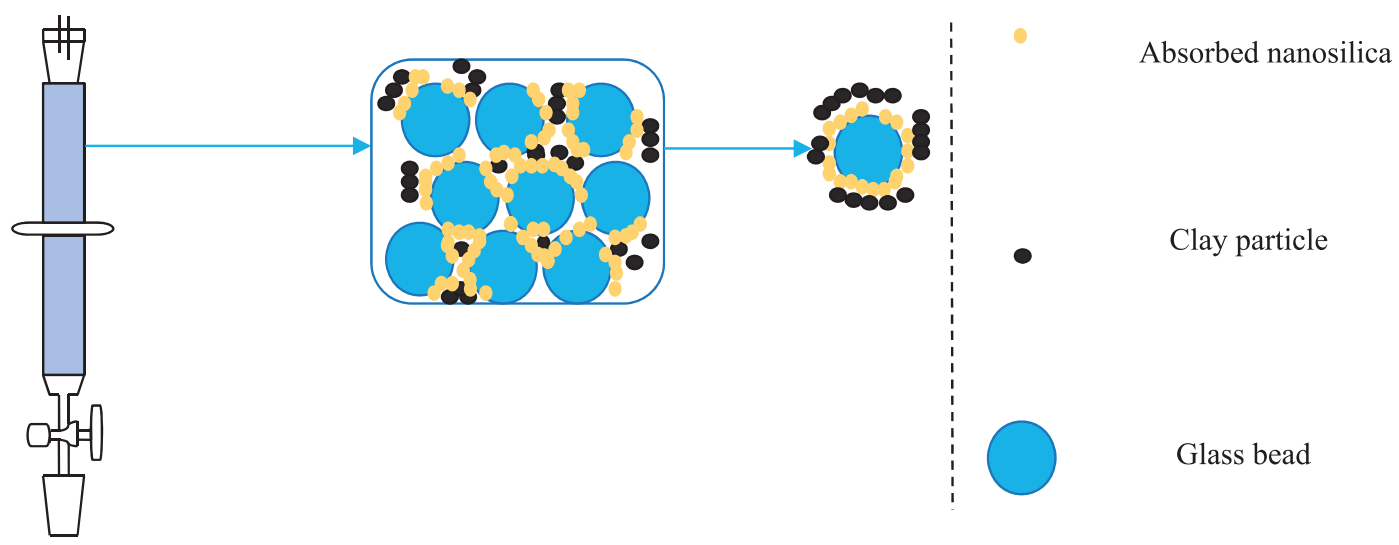

Fig. 5. Schematic representation of clay absorbance on glass beads. 


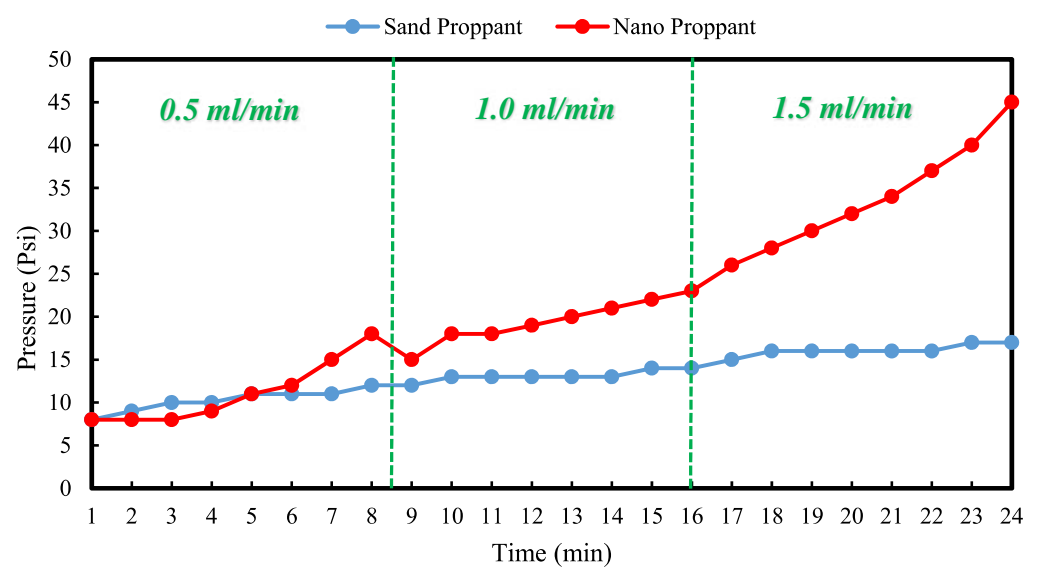

(a)

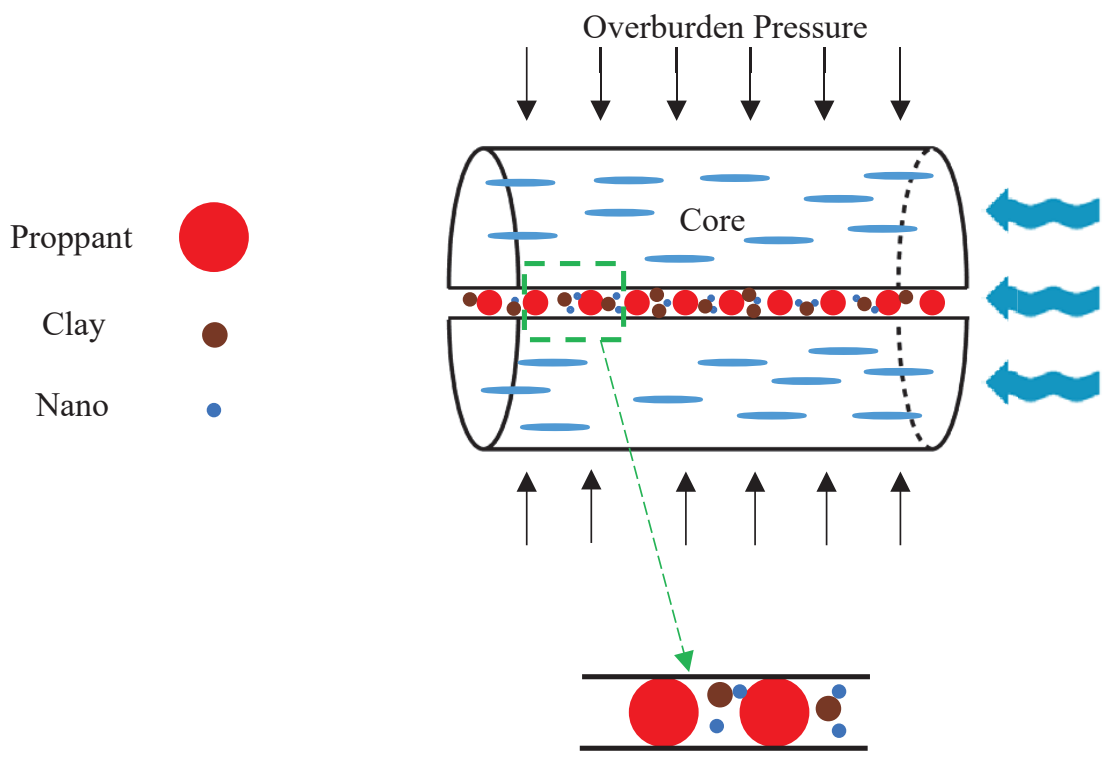

(b)

Fig. 6. The result of the used nanosilica in core-flood: (a) Variation of the pressure versus time during displacement test at injection rates of $0.5,1.0$, and $1.5 \mathrm{ml} / \mathrm{min}$; (b) A schematic representation of the effect nanosilica during core-flood test.

surrounding a nanoparticle in solution (Clogston and Patri, 2011). One of the most common uses of $\mathrm{ZP}$ data is to relate it with colloid stability. Guidelines classify NP-dispersions with $\mathrm{ZP}$ values of $> \pm 30 \mathrm{mV}, \pm 20-30 \mathrm{mV}, \pm 10-20 \mathrm{mV}$, and \pm 0 $10 \mathrm{mV}$ as highly stable, moderately stable, relatively stable, and highly unstable, respectively (Patel and Agrawal, 2011). In addition, nanoparticles with ZP greater than $+30 \mathrm{mV}$ are considered strongly cationic (Clogston and Patri, 2011).

Fig. 5 graphically illustrates the process by which the clay particles are absorbed on glass beads.

In the second set of experiments, a sandstone core sample was fractured along its longitudinal axis, as already mentioned. This was majorly done to simulate a fractured medium made during the hydraulic fracturing process and to investigate nanosilica effectiveness in reducing fines migration during hydraulic fracturing. Separately, $10 \mathrm{gr}$ of sand proppant and the mixture of $4 \mathrm{gr}$ nanosilica with $10 \mathrm{gr}$ sand proppant were put between the sub plugs. Then, core flooding tests were conducted with a mixture of clay particles in $50000 \mathrm{ppm} \mathrm{NaCl}$ solution as the injection fluid. The tests were started at a rate of $0.5 \mathrm{ml} / \mathrm{min}$ and then increased to 1.0 and $1.5 \mathrm{ml} / \mathrm{min}$, in which each of them was continued for about $8 \mathrm{~min}$. The injection rate was increased stepwise because it is of high importance to examine nanosilica performance at high injection rates where fines migration is much more possible.

The pressure across the core sample was recorded using a pressure transducer. The recorded data are shown in Fig. 6(a). As presented in this figure, pressure rise, which is qualitatively equivalent to permeability decline by Darcy's law, is higher in the case where nanosilica particles were mixed with sand proppant. This is due to the fact that clays are absorbed on nanosilica particles through molecular interactions. This occurrence causes a reduction in the effective fracture thickness, directly resulting in reduced average permeability (the average of matrix and fracture permeability). As a result, the pressure raised more in the case where clays movement exists. 
This observation indicates that fines migration, or in other words, clays movement can be effectively prevented by nanosilica particles. Although in this case the fracture was made artificially, in real cases, the fracture is created hydraulically with the solution containing nanoparticles. In other words, during hydraulic fracturing the nanoparticles will be settled through the fracture, making fines stable at their original locations. Therefore, fines migration is prevented without permeability declines. Fig. 6(b) illustrates the process of clay particles attachment to nanosilica particles within the fracture medium.

To further investigate our findings, a theoretical framework based on DLVO theory (Xie et al., 2016) was developed in this study. Based on this theory, disjoining pressure calculations can be regarded as a representative tool of interactive forces between two interfaces. By definition, disjoining pressure is the sum of Van-der-Waals, electrical and structural forces. On a quantitative point of view, Van-der-Waals forces are negative, but the two others are positive. Van-der-Waals forces are assumed to act as attractive forces; thus, their measurement indicates the attachment strength of two interfaces at the molecular level. In the current study, Van-der-Waals forces were calculated by the following equation (Xie et al., 2016):

$$
\Pi_{\text {Van }}(h)=\frac{-A\left(\frac{15.96 h}{\lambda}+2\right)}{12 \pi h^{3}\left(1+\frac{5.32 h}{\lambda}\right)^{2}}
$$

where $\lambda$ stands for London Wave-length, $A$ denotes the Hamaker constant, and $h$ expresses the distance between two interfaces. Specifically, referring to the work of Xie et al. (2016), Hamaker constant was set to be $0.81 \times 10^{-20} \mathrm{~J}$ and $100 \mathrm{~nm}$ considered as $\lambda$.

Electrical force does exist due to electric changes activities. Using Zeta potential values, the following equation was used for electrical forces to be calculated (Xie et al., 2016):

$$
\Pi_{\text {electrical }}(h)=n_{b} k_{B} T\left[\frac{2 \psi_{r 1} \psi_{r 2} \cosh (\kappa h)-\psi_{r 1}^{2}-\psi_{r 2}^{2}}{(\sinh (\kappa h))^{2}}\right]
$$

where $n_{b}$ expresses the bulk solution ion density, $k_{B}$ displays the Boltzmann constant, $\psi_{r 1}$ and $\psi_{r 2}$ stand for the reduced Zeta potentials and $\kappa$ denotes mutual Debye-Huckel double layer length, which can be calculated by (Xie et al., 2016):

$$
\kappa=\sqrt{\frac{2 e^{2} z^{2} n_{b}}{\varepsilon_{0} \varepsilon_{r} k_{B} T}}
$$

where $e$ shows the electron charge which is equal to $1.60 \times 10^{-19} \mathrm{C}, z$ represents valence of a symmetrical electrolyte solution which is 1 for $\mathrm{NaCl}, \varepsilon_{0}$ denotes the dielectric permittivity of vacuum, $8.854 \times 10^{-12}, \varepsilon_{r}$ is relative permittivity of an electrolyte solution, which was considered 78.4 based on the work of Xie et al. (2016).

Compared to Van-der-Waals and electrical forces, structural forces are short range. Their effects would, therefore, vanish as the distance between molecules increases. The following formula was applied to calculate structural forces (Xie et al., 2016):

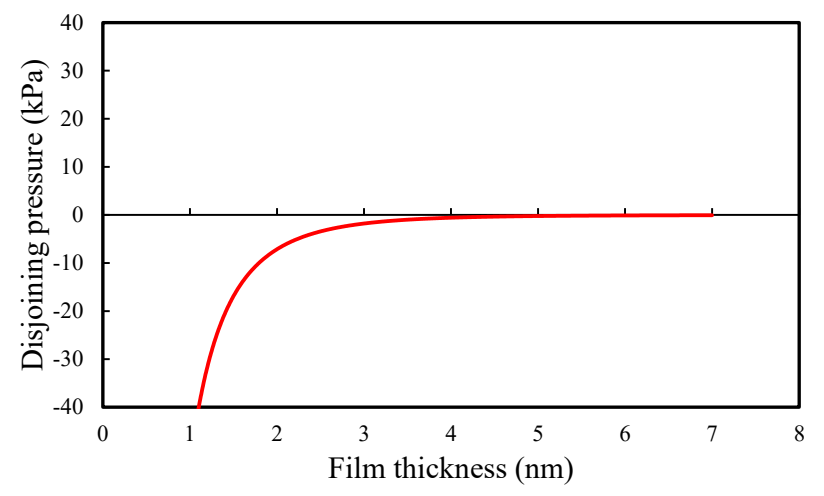

Fig. 7. Total disjoining pressure as a function of separation distance in the presence of nanosilica at $25^{\circ} \mathrm{C}$.

$$
\Pi_{\text {Structural }}=A_{k} \exp \left(\frac{-h}{h_{s}}\right)
$$

where $A_{k}$ is a coefficient and $h_{s}$ is the characteristic decay length for the exponential model. In this study, $A_{k}$ was assumed to be $1.5 \times 10^{10} \mathrm{~Pa}$ and $h_{s}$ is $0.05 \mathrm{~nm}$ (Xie et al., 2016).

As mentioned by Xie et al. (2016), a negative disjoining pressure indicates absorbance process. Fig. 7 displays the results of disjoining pressure calculations. As illustrated in this figure, the disjoining pressure value is negative, which theoretically confirms our experimental findings.

\section{Conclusions}

In this experimental work, a new remedy is proposed for proper treatment of fines migration phenomenon during hydraulic fracturing. For this reason, a new nanosilica particle was adopted from the literature for resolving fines migration for the first time. Two sets of experiments were taken into consideration for investigating the nanosilica effect. The first test set was static and qualitative which was implemented using glass beads funnel test. The second set of experiment was dynamic which was executed by the core-flood apparatus. Moreover, DLVO theory was utilized to detect the prevailing mechanism of nanosilica particles in this study. As a result, the applied nanosilica in this study has a positive impact on reducing the degree of fines migration in both dynamic and static conditions. The calculation of disjoining pressure demonstrates that the negatively charged clay particles are absorbed on the sand proppants by reason of positively charged nanosilica particles available in solution. To this end, the synthesized nanosilica in this study is of crucial importance for treating fines migration during the hydraulic fracturing operation.

Open Access This article is distributed under the terms and conditions of the Creative Commons Attribution (CC BY-NC-ND) license, which permits unrestricted use, distribution, and reproduction in any medium, provided the original work is properly cited. 


\section{References}

Ahmadi, M.A., Shadizadeh, S.R. Induced effect of adding nano silica on adsorption of a natural surfactant onto sandstone rock: Experimental and theoretical study. J. Pet. Sci. Eng. 2013, 112: 239-247.

Assef, Y., Arab, D., Pourafshary, P. Application of nanofluid to control fines migration to improve the performance of low salinity water flooding and alkaline flooding. J. Pet. Sci. Eng. 2014, 124: 331-340.

Bao, J., Liu, H., Zhang, G., et al. Fracture propagation laws in staged hydraulic fracturing and their effects on fracture conductivities. Pet. Explor. Dev. 2017, 44(2): 306-314.

Binks, B.P. Particles as surfactants-similarities and differences. Curr. Opin. Colloid Interface Sci. 2002, 7(1-2): 21-41.

Borisov, A.S., Husein, M., Hareland, G. A field application of nanoparticle-based invert emulsion drilling fluids. J. Nanopart. Res. 2015, 17(8): 340.

Bortolan, N.L., Khanna, A., Kotousov, A. Conductivity and performance of hydraulic fractures partially filled with compressible proppant packs. Int. J. Rock Mech. Min. 2015, 74: 1-9.

Choolaei, M., Rashidi, A.M., Ardjmand, M., et al. The effect of nanosilica on the physical properties of oil well cement. Mater. Sci. Eng. 2012, 538: 288-294.

Cipolla, C.L. Modeling production and evaluating fracture performance in unconventional gas reservoirs. J. Pet. Technol. 2009, 61(9): 84-90.

Civan, F.P. Single-phase formation damage by fines migration and clay swelling, in Reservoir formation damage (third edition), edited by F.P. Civan, Kidlington, Oxford, pp. 235-275, 2016.

Clogston, J.D., Patri, A.K. Zeta potential measurement, in Characterization of nanoparticles intended for drug delivery, edited by E.M. Scott, Clifton, New Jersey, pp. 63-70, 2011.

Contreras, O., Hareland, G., Husein, M., et al. Application of in-house prepared nanoparticles as filtration control additive to reduce formation damage. Paper SPE 168116 Present at SPE International Symposium and Exhibition on Formation Damage Control, Lafayette, Louisiana, 2628 February, 2014a.

Contreras, O., Hareland, G., Husein, M., et al. Experimental investigation on wellbore strengthening in shales by means of nanoparticle-based drilling fluids. Paper SPE 170589 Presented at SPE Annual Technical Conference and Exhibition, Amsterdam, The Netherland, 27-29 October, 2014b.

Contreras, O., Hareland, G., Husein, M., et al. Wellbore strengthening in sandstones by means of nanoparticlebased drilling fluids. Presented at SPE deepwater drilling and completions conference, Galveston, Texas, USA, 1011 September, 2014c.

Dai, C., Wang, S., Li, Y., et al. The first study of surface modified silica nanoparticles in pressure-decreasing application. RSC Adv. 2015, 5(76): 61838-61845.

Divandari, H., Hemmati-Sarapardeh, A., Schaffie, M., et al. Integrating synthesized citric acid-coated magnetite nanoparticles with magnetic fields for enhanced oil recovery: Experimental study and mechanistic understanding. J. Pet. Sci. Eng. 2019, 174: 425-436.

Driscoll, V.J. Multiple producing intervals to suppress coning. U.S. Patent No 3,638,731, 1972.

Ezeonyeka, N.L., Hemmati-Sarapardeh, A., Husein, M.M. Asphaltenes adsorption onto metal oxide nanoparticles: A critical evaluation of measurement techniques. Energy Fuels 2018, 32(2): 2213-2223.

Franco, C.A., Nassar, N.N., Corts, F.B. Removal of oil from oil-in-saltwater emulsions by adsorption onto nanoalumina functionalized with petroleum vacuum residue. J. Colloid Interface Sci. 2014, 433: 58-67.

Gao, C., Miska, S., Yu, M., et al. Effective enhancement of wellbore stability in shales with new families of nanoparticles. Paper SPE 180330 Presented at SPE Deepwater Drilling and Completions Conference, Galveston, Texas, 14-15 September, 2016.

Guo, T., Zhang, S., Wang, L., et al. Optimization of proppant size for frac pack completion using a new equipment. J. Pet. Sci. Eng. 2012, 96: 1-9.

Haddad, M., Sepehrnoori, K. Simulation of hydraulic fracturing in quasi-brittle shale formations using characterized cohesive layer: Stimulation controlling factors. J. Unconv. Oil Gas Res. 2015, 9: 65-83.

Hoxha, B.B., Oort, E.V., Daigle, H. How do nanoparticles stabilize shale? Paper SPE 184574 Present at SPE International Conference on Oilfield Chemistry, Montgomery, Texas, 3-5 April, 2017.

Huang, T., Evans, B.A., Crews, J.B., et al. Field case study on formation fines control with nanoparticles in offshore applications. Paper SPE 135088 Presented at SPE Annual Technical Conference and Exhibition, Florence, Italy, 1922 September, 2010.

Khanna, A., Kotousov, A., Sobey, J., et al. Conductivity of narrow fractures filled with a proppant monolayer. J. Pet. Sci. Eng. 2012, 100: 9-13.

Li, Q., Xing, H., Liu, J., et al. A review on hydraulic fracturing of unconventional reservoir. Petroleum 2015, 1(1): 8-15.

Liu, N., Zhang, Z., Zou, Y., et al. Propagation law of hydraulic fractures during multi-staged horizontal well fracturing in a tight reservoir. Pet. Explor. Dev. 2018, 45(6): 11291138.

Lv, Q., Li, Z., Li, B., et al. Study of nanoparticlesurfactantstabilized foam as a fracturing fluid. Ind. Eng. Chem. Res. 2015, 54(38): 9468-9477.

Lv, Q., Li, Z., Li, B. Enhancing fluid-loss control performance of liquid $\mathrm{CO}_{2}$ fracturing fluid by foaming with highpressure nitrogen, in Proceedings of the International Field Exploration and Development Conference 2017, edited by Z. Qu and J. Lin, Singpore, pp. 1568-1575, 2019.

Moghadasi, R., Rostami, A., Hemmati-Sarapardeh, A., et al. Application of nanosilica for inhibition of fines migration during low salinity water injection: Experimental study, mechanistic understanding, and model development. Fuel 2019a, 242: 846-862. 
Moghadasi, R., Rostami, A., Tatar, A., et al. An experimental study of nanosilica application in reducing calcium sulfate scale at high temperatures during high and low salinity water injection. J. Pet. Sci. Eng. 2019b, 179: 7-18.

Parvazdavani, M., Masihi, M., Ghazanfari, M.H. Monitoring the influence of dispersed nano-particles on oilwater relative permeability hysteresis. J. Pet. Sci. Eng. 2014, 124: 222-231.

Patel, V.R., Agrawal, Y. Nanosuspension: An approach to enhance solubility of drugs. J. Adv. Pharm. Technol. Res. 2011, 2(2): 81-87.

Sanematsu, P., Shen, Y., Thompson, K., et al. Image-based stokes flow modeling in bulk proppant packs and propped fractures under high loading stresses. J. Pet. Sci. Eng. 2015, 135: 391-402.

Shokrlu, Y.H., Babadagli, T. Viscosity reduction of heavy oil/bitumen using micro- and nano-metal particles during aqueous and non-aqueous thermal applications. J. Pet. Sci. Eng. 2014, 119: 210-220.

Wen, Q., Zhang, S., Wang, L., et al. The effect of proppant embedment upon the long-term conductivity of fractures. J. Pet. Sci. Eng. 2007, 55(34): 221-227.
Xie, Q., Saeedi, A., Pooryousefy, E., et al. Extended dlvobased estimates of surface force in low salinity water flooding. J. Mol. Liq. 2016, 221: 658-665.

Yuan, B., Wood, D.A. Formation Damage During Improved Oil Recovery: Fundamentals and Applications. Oxford, UK, Gulf Professional Publishing, 2018.

Yuan, H., Shapiro, A.A. Induced migration of fines during waterflooding in communicating layer-cake reservoirs. J. Pet. Sci. Eng. 2011, 78(34): 618-626.

Zakaria, M., Husein, M.M., Harland, G. Novel nanoparticlebased drilling fluid with improved characteristics. Paper SPE 156992 Presented at SPE international oilfield nanotechnology conference and exhibition, Noordwijk, The Netherlands, 12-14 June, 2012.

Zeinijahromi, A., Vaz, A., Bedrikovetsky, P. Well impairment by fines migration in gas fields. J. Pet. Sci. Eng. 2012, 88-89: 125-135.

Zhang, J., Ouyang, L., Zhu, D., et al. Experimental and numerical studies of reduced fracture conductivity due to proppant embedment in the shale reservoir. J. Pet. Sci. Eng. 2015, 130: 37-45. 